\title{
Reciprocal regulation between microRNAs and epigenetic machinery in colorectal cancer (Review)
}

\author{
FENG WANG $^{1}$, YANLEI MA ${ }^{1}$, HUAMIN WANG ${ }^{2}$ and HUANLONG QIN ${ }^{1}$ \\ ${ }^{1}$ Department of Surgery, Shanghai Tenth People's Hospital Affiliated to Tongji University, Shanghai 200072, P.R. China; \\ ${ }^{2}$ Department of Pathology, The University of Texas MD Anderson Cancer Center, Houston, TX 77030, USA
}

Received January 20, 2015; Accepted February 24, 2016

DOI: $10.3892 / 01.2017 .5593$

\begin{abstract}
Epigenetics encompasses changes in DNA methylation, histone and chromatin structure, and non-coding RNAs, specifically microRNA (miRNA) expression. Recent advances in the rapidly evolving field of colorectal cancer (CRC) epigenetics have revealed a complicated network of reciprocal interconnections between miRNAs and other epigenetic machinery. On the one hand, miRNA expression may be regulated by epigenetic mechanisms including DNA methylation and histone modifications. However, miRNAs may affect the epigenetic machinery by directly targeting its enzymatic components. In this study, we focus on the colorectal miRNA expression profile and further illustrate the reciprocal regulation in CRC, with the aim of offering new insights into the strategies of combatting the disease.
\end{abstract}

\section{Contents}

1. Introduction

2. Deregulation of miRNAs in CRC

3. Function of miRNAs in CRC

4. Epigenetic regulation of miRNAs in CRC

5. miRNA regulatory effects on epigenetic machinery in CRC

6. miRNAs mediate crosstalk between epigenetic regulators in $\mathrm{CRC}$

7. Clinical significance and future prospects

Correspondence to: Dr Feng Wang or Professor Huanlong Qin, Department of Surgery, Shanghai Tenth People's Hospital Affiliated to Tongji University, 301 Middle Yanchang Road, Shanghai 200072, P.R. China

E-mail:wf03@live.com

E-mail: hlong_qin@live.com

Key words: colorectal cancer, microRNA, DNA methylation, histone modifications, epigenetics

\section{Introduction}

Colorectal cancer (CRC) is one of the most commonly diagnosed cancers worldwide, ranking as the third most prevalent and fourth most frequent cause of cancer-related mortality (1). In the early era of modern molecular biology research, CRC was considered to be a disease caused by genetic alterations, which influenced the gene product by changing the amino acid sequence of a protein. With advances in cancer research, however, more studies have focused on the alterations in the regulation of gene expression that are independent from the DNA sequence of the cell and are referred to as 'epigenetic' changes. Epigenetic changes are likely to be a major feature of cancer, and the most prominent epigenetic modifications involve the aberrant methylation of $\mathrm{CpG}$ islands (CGIs) and deacetylation or methylation of histone proteins (2).

MicroRNAs (miRNAs or miRs) are non-coding, endogenous small RNAs that bind the 3' untranslated regions (UTRs) of their target messenger RNA (mRNA) transcripts to suppress protein translation or cause mRNA degradation (3). These newly identified small molecules have been classified as epigenetic since the regulation of mRNAs does not directly involve changing the DNA sequence. In the last decades, emerging evidence has indicated that miRNAs are deregulated in CRC and are directly connected with the epigenetic machinery, playing a significant role in the occurrence and progression of CRC.

In this review, we summarise recent findings on miRNAs in $\mathrm{CRC}$, in particular the reciprocal regulation between miRNAs and other epigenetic machinery, to better understand the epigenetic mechanisms that contribute to CRC carcinogenesis and to identify new avenues for the diagnosis and treatment of this disease.

\section{Deregulation of miRNAs in CRC}

miRNAs are short 18-24 nucleotide single-stranded RNAs that mediate post-transcriptional gene repression (4). The miRNA family is comprised of gene miRNA clusters, which have high homogeneity. In animals, primary miRNA genes are transcribed by RNA polymerase II and are subsequently processed to precursor hairpin miRNAs (pre-miRNAs) that are $\sim 70 \mathrm{nt}$ long by Drosha in the nucleus. The pre-miRNAs are then transported to the cytoplasm, where they are recognised 
and processed by the RNAse III enzyme Dicer into mature miRNAs of $\sim 22 \mathrm{nt}$. The mature miRNAs induce the degradation of mRNAs and downregulate the target genes through the imperfect binding of the RNA-induced silencing complex to the $3^{\prime}$ UTR of target mRNAs $(5,6)$.

The first miRNA was reported in 1993, when the Caenorhabditis elegans heterochronic gene lin- 4 was identified as encoding small RNAs with antisense complementarity to lin-14 (7). At the time of this review, 1,881 precursors and 2,588 mature human miRNAs have been annotated in the latest version of the miRBase (available at www.mirbase.org) (8). On the one hand, miRNAs are highly evolutionarily conserved across different species; on the other hand, the expression pattern of specific miRNAs may be correlated using a particular type of tissue. Compared with corresponding normal tissues, miRNA expression profiles in tumours have indicated widespread changes during tumourigenesis and appear to be related to the developmental stage of cancers as well as being associated with other clinical features (9-12).

With the application of high-throughput screening technology, including microarray-based miRNA profiling platforms and next-generation sequencing (NGS) approaches, more studies have focused on searching for biomarkers by identifying different miRNA expressions in different types of cancer. To date, a number of aberrantly expressed miRNAs and their gene targets have been identified in CRC. The first study to investigate a miRNA alteration in CRC was performed in 2003, in which miR-143 and miR-145 were expressed at reduced steady-state levels at the adenomatous and cancer stages of CRC (13). In another study, 37 miRNAs with various expression levels were identified in CRC using comprehensive array-based analyses in $84 \mathrm{CRC}$ and matched normal colonic tissues (14). As a new emerging throughput screening platform, NGS technology easily enriches, detects and analyses miRNAs using a genome-wide scale. Moreover, the combination of miRNA and transcriptome sequencing enables the prediction of miRNA target genes, which aids in the identification of new and known miRNAs from a systematic and functional perspective. Using NGS technology in normal, tumour and metastasis tissue samples from the same patients with CRC, an earlier study investigated the complete set of miRNAs and their potential downstream regulated genes as well as the signalling network, and explored the power of miRNA-1 response prediction in individual patients (15).

Despite the use of various detection methods, including microarray, sequencing, real-time polymerase chain reaction-based approaches and in situ hybridisation, a high consistency of miRNA expression profiles exists among these studies, which indicates that these miRNAs are essential elements in cancer progression (16-19).

\section{Function of miRNAs in CRC}

As each miRNA has several different mRNA targets, miRNA genes are predicted to represent $\sim 3 \%$ of the human genome, whereas $\sim 30 \%$ of the genes are regulated by miRNAs (20). Evidence has demonstrated that miRNAs act either as tumour suppressors by suppressing the expression of target oncogenes, or as proto-oncogenes by inhibiting the expression of tumour suppressor genes (TSGs) (21-24). Both effects correlate with cancer development and its progression in $\operatorname{CRC}(11,25,26)$.

miRNAs and Wnt/ $\beta$-catenin pathway. The deregulation of the $\mathrm{Wnt} / \beta$-catenin pathway is one of the earliest events during CRC development. In this pathogenic pathway, $\beta$-catenin acts as a transcriptional activator and upregulates the expression of Wnt target genes. Overexpression of constitutively active $\beta$-catenin may result in colorectal tumourigenesis (27). Through in vitro and in vivo experiments, Ma et al proved that miRNA-17-92 increases the expression of $\beta$-catenin indirectly by targeting P130, and subsequently promotes the tumourigenesis and progression of CRC (28). Strillacci et al revealed that miR-101 regulates Wnt/ $\beta$-catenin signalling in CRC through the strong impairment of $\beta$-catenin nuclear accumulation and $\beta$-catenin-driven transcriptional activity, following the control of downstream target gene expression and malignant phenotype in cancer cells (29).

miRNAs and cancer stem cells (CSC)s. CSCs are a group of heterogeneous cells that are vital for the initiation and progression of cancers, including CRC. The Wnt pathway plays an essential role in the induction of the symmetrical cell division (SCD) of CSCs, which disturbs the homeostasis of the stem cell pool and leads to carcinogenesis $(30,31)$. miRNA-146a was identified by Hwang et al as an activator of the Wnt pathway in CRCSCs by stabilising $\beta$-catenin, which directs SCD to promote CRC progression. Notably, the study uncovered an upstream regulatory mechanism of miR-146a, in which Snail activates miR-146a transcription via a $\beta$-catenin-TCF4 complex. A feedback circuit of Snail-miR-146a- $\beta$-catenin loops exists in CRCSCs to maintain Wnt activity using a miRNA-dependent regulation method (32).

miRNAs and epithelial-to-mesenchymal transition (EMT). EMT is a cellular process of converting polarised epithelial cells into mesenchymal cells. During this process, cancer cells acquire malignant, migratory and invasive capabilities (33). The activation of EMT in CRC enables the cancer cells to detach, migrate and disseminate through the blood or lymphatic vessels, suggesting a mechanistic role of EMT in CRC metastasis.

A range of miRNAs were identified as regulators in this CRC process. For example, miR-29c expression in primary CRC and distant liver metastases tissues was observed to be negatively related to the mRNA levels of E-cadherin and vimentin, which are known to be specifically upregulated and established as markers of EMT (34). Moreover, ectopic miR-29c expression suppresses the expression of these EMT markers and induces morphological transformations to reverse EMT in CRC cells (34). Additional mechanistic research revealed that GNA13 and PTP4A are direct targets of miR-29c that act through the ERK/GSK3 $\beta / \beta$-catenin and AKT/GSK $3 \beta / \beta$-catenin pathways, respectively, to regulate EMT (34).

Using an azoxymethane and dextran sodium sulfate-induced colitis-associated tumour mouse model, Rokavec et al demonstrated that exposure of CRC cells to the cytokine IL-6 represses the miR-34a gene by activating the STAT3 transcription factor. Furthermore, the IL-6 receptor, which mediates IL-6-dependent STAT3 activation, was identified as a direct miR-34a target. 
Such miRNA-related self-stabilising circuits consisting of IL-6R/STAT3/miR-34a are crucial for the induction of EMT and capacitation of metastasis in CRC cells (35).

miRNAs and epidermal growth factor receptor (EGFR) pathway. Human EGFR comprises an extracellular ligand-binding domain and an intracellular domain with tyrosine kinase activity. The selective induction of EGFR activates two major downstream signalling pathways, namely $\mathrm{KRAS} / \mathrm{RAF} / \mathrm{ERK}$ and PI3K/AKT, and is responsible for the progression of a broad spectrum of solid tumours, including CRC.

KRAS is described as a major driver of CRC progression and may be regulated directly by a number of miRNAs with tumour suppressor functions, including miR-143 $(36,37)$, miR-145 (37), miR-18a* (38), miR-30b (39) and let-7 (40). In contrast, KRAS upregulates the expression of oncogenic miR-200c, miR-221/222, miR-181a and miR-210 in CRC cells (41). In an inflammatory bowel disease-associated CRC study, researchers identified a correlation between miR-133a, miR-143, miR-145 and miR-223 dysregulation and alteration of PI3K/Akt signalling. Furthermore, the authors observed that miR-223 directly targeted IGF1R to regulate this pathway, representing molecular links between inflammation and cancer (37).

Additionally, the EGFR pathway serves as an essential anticancer agent target (42), and anti-EGFR chemotherapy has been routinely used in advanced CRC. However, a response to this therapy was observed in less than $40 \%$ of patients with KRAS wild-type tumours (43). Additional factors are required to facilitate patient selection for this therapy to avoid the prescription of ineffective and potentially harmful side effects. In related studies, miRNAs including miR-31-3p (44), let-7 (45), miR-181a (46) and miR-143 (47) have been identified as significant markers for predicting an effective response in patients treated with anti-EGFR therapy.

\section{Epigenetic regulation of miRNAs in CRC}

Since aberrant miRNAs are well recognised as representing the hallmark of and playing a key role in several biological processes of CRC, increasing numbers of studies have focused on exploring the mechanisms responsible for disturbed miRNA expression. Dysregulated miRNAs are known as epigenetic alterations. Notably, a previous study has suggested that gene encoding for miRNAs may be affected by the same epigenetic regulatory mechanisms that modulate any other protein-coding genes (48). We summarise the altered miRNAs regulated by epigenetic factors in Table I, including promoter methylation, histone acetylation and chromatin changes in CRC. The data are derived from various array platforms and supported by validation experiments and function assays (49-72).

DNA methylation-mediated regulation of miRNAs in CRC. The chemical modification of DNA methylation is mediated by DNA methyltransferases (DNMTs), which catalyse the covalent attachment of a methyl group to the 5' carbon of cytosine in $\mathrm{CpG}$ dinucleotides. The majority of $\mathrm{CpGs}$ are maintained in a methylated state, whereas the $\mathrm{CpGs}$ located in CGIs, local enrichments of $\mathrm{CpG}$ sequences, are normally unmethylated. The methylation of CGIs in promoters and start sites inhibits interactions with transcription factors and induces a reduction in gene expression (73). A comprehensive analysis of miRNA gene sequences has revealed that $\sim 50 \%$ are associated with CGIs, suggesting that they could be subjected to a DNA methylation mechanism of regulation (74).

Hypermethylation-silenced miRNAs in CRC. Evidence has confirmed that DNA methylation may be responsible for the altered expression of miRNAs in CRC by silencing potential tumour suppressor miRNAs. The DNA demethylating agent 5-aza-2'-deoxycytidine (5-AZA) reduces the methylation levels of genes by covalently binding to DNMTs and inhibiting their function (75), and is widely applied in the search for methylation-regulated miRNAs. By combining the treatment of CRC cells using 5-AZA and high-throughput analysis, eight miRNAs were identified as novel miRNAs regulated by DNA methylation (59). The authors subsequently investigated the functions of these hypermethylation-silenced miRNAs by ectopically expressing select candidates, which resulted in the repression of proliferation and the migration of cancer cells (59). After treating the CRC cells with 5-AZA and the histone deacetylase (HDAC) inhibitor trichostatin A, Grady et al demonstrated that the expression of miR-342 is commonly suppressed by hypermethylation in CRC and that the reconstitution of miR-342 in the HT-29 cells induced apoptosis, implying its function as a pro-apoptotic tumour suppressor. More significantly, the methylated CGI located in the promoter of EVL, which has been proven to be the host gene of miR-342, has a higher frequency of methylation in cancer and adenoma samples compared with normal samples. This study addressed a novel mechanism for silencing intronic miRNAs by epigenetic alterations of cognate host genes in CRC (57).

A similar approach aimed at identifying epigenetically regulated miRNAs was represented by the miRNA profiling of CRC cells genetically deficient for the DNA methyltransferase enzymes. DNA hypomethylation induces a release of miRNA silencing in cancer cells. One of the primary targets is miRNA-124a, which is embedded in a large CGI and is capable of targeting cyclin D kinase 6 (CDK6); CDK6 has an impact on the phosphorylation status of downstream effector retinoblastoma TSG (51). To identify methylation-silenced miRNAs and to clarify their role in CRC, our group performed a microarray analysis to screen for miRNAs in CRC cells using 5-AZA treatment or a genetic knockdown of DNA methyltransferases. We observed that miR-149 was epigenetically silenced in CRC and that the downregulation of miR-149 was associated with the hypermethylation of the neighbouring CGI. The transfection of miR-149 inhibited the cell growth and invasion of CRC cells in vitro by targeting specificity protein 1 (67).

Methylation-regulated miRNAs have been observed to be closely linked with the progression of CRC. Balaguer et al reported that methylation of the miR-137 CGI was a cancer-specific event that was observed in virtually all CRC cell lines, in $82 \%$ of adenomas, in $82 \%$ of CRCs but in only $14 \%$ of normal mucosae, suggesting that the results constituted an early event in colorectal carcinogenesis (58). Other studies in CRC samples identified five miRNAs that were downregulated and located around or on a CGI, and 5-AZA-restored 
Table I. Epigenetically regulated miRNAs in CRC.

\begin{tabular}{|c|c|c|c|c|c|}
\hline miRNA & $\begin{array}{c}\text { Chromosomal } \\
\text { location }\end{array}$ & Regulation & $\begin{array}{l}\text { Target } \\
\text { gene }\end{array}$ & $\begin{array}{c}\text { Expression } \\
\text { in CRC }\end{array}$ & References \\
\hline $\mathrm{miR}-34 \mathrm{~b} / \mathrm{c}$ & $11 q 23.1$ & Hypermethylation & $\begin{array}{c}\text { CDK6, c-MYC; } \\
\text { E2F3 }\end{array}$ & Downregulated & (49) \\
\hline \multirow[t]{3}{*}{$\operatorname{miR}-124 a$} & 8p23.1 (miR-124a-1) & & & & \\
\hline & 8q12.3 (miR-124a-2) & Hypermethylation & CDK6 & Downregulated & $(50)$ \\
\hline & $20 q 13.33(\mathrm{miR}-124 a-3)$ & & & & \\
\hline miR-9-1 & $1 \mathrm{q} 22$ & Hypermethylation & & Downregulated & $(51)$ \\
\hline miR-1/133a cluster & $20 q 13.33$ & Hypermethylation & & Downregulated & $(52)$ \\
\hline miR-124a & $8 \mathrm{p} 23.1$ & Hypermethylation & & Downregulated & (53) \\
\hline miR-342 & $14 \mathrm{q} 32.2$ & Hypermethylation & & Downregulated & $(54)$ \\
\hline miR-137 & $1 \mathrm{p} 21.3$ & Hypermethylation & LSD1 & Downregulated & $(55)$ \\
\hline miR-129-2 & $11 \mathrm{p} 11.2$ & Hypermethylation & & Downregulated & $(51)$ \\
\hline miR-941 & $20 q 13.33$ & Hypermethylation & & Downregulated & $(56)$ \\
\hline $\operatorname{miR}-1237$ & 11 & Hypermethylation & & Downregulated & $(56)$ \\
\hline miR-1247 & 14 & Hypermethylation & & Downregulated & $(56)$ \\
\hline miR-17-92 cluster & $13 q 31.3$ & $\begin{array}{l}\text { Histone } \\
\text { deacetylation }\end{array}$ & $\begin{array}{l}\text { PTEN, BCL2L11, } \\
\text { CDKN1A }\end{array}$ & Upregulated & $(57)$ \\
\hline miR-34a & $1 \mathrm{p} 36.22$ & Hypermethylation & $\begin{array}{c}\text { c-Met, Snail, } \\
\beta \text {-catenin }\end{array}$ & Downregulated & (58) \\
\hline miR-128 & $2 q 21.3$ & Hypermethylation & NEK2 & Downregulated & (59) \\
\hline miR-148a & $7 \mathrm{p} 15.2$ & Hypermethylation & & Downregulated & $(60)$ \\
\hline miR-126 & $9 q 34.3$ & Hypermethylation & VEGF & Downregulated & (61) \\
\hline $\operatorname{miR}-27 b$ & $9 q 22.32$ & Hypermethylation & VEGFC & Downregulated & (62) \\
\hline miR-149 & $2 q 37.3$ & Hypermethylation & SP1 & Downregulated & (63) \\
\hline miR-497/195 & $17 \mathrm{p} 13.1$ & Hypermethylation & & Downregulated & (64) \\
\hline miR-212 & $17 \mathrm{p} 13.3$ & Hypermethylation & MnSOD & Downregulated & $(65)$ \\
\hline miR-200c/141 & $12 \mathrm{p} 13.31$ & Hypomethylation & $\begin{array}{l}\text { ZEB1, ETS1, } \\
\text { FLT1 }\end{array}$ & Upregulated & (66) \\
\hline miR-345 & $14 q 32.2$ & Hypermethylation & BAG3 & Downregulated & (67) \\
\hline miR-373 & $19 q 13.42$ & Hypermethylation & RAB22A & Downregulated & (68) \\
\hline
\end{tabular}

CRC, colorectal cancer; miR/miRNA, microRNA.

expression of three miRNAs (namely miR-9, miR-129 and miR-137) in three CRC cell lines. Methylation of the miR-9-1, miR-129-2 and miR-137 CGIs was observed in CRC cell lines and in primary CRC tumours, but not in normal colonic mucosae. Furthermore, the methylation of miR-9-1 occurred more frequently in the advanced stages of CRC and was associated with nodal invasion $(\mathrm{P}=0.008)$, vascular invasion $(\mathrm{P}=0.004)$ and distant metastasis $(\mathrm{P}=0.016)(52)$. Using a case-control study containing 94 primary colon cancer samples with and without liver metastases, Siemens et al determined CGI methylation frequencies of miR-34 promoters and prognostic values. Their results revealed that miR-34a methylation was strongly associated with metastasis to the liver $(\mathrm{P}=0.003)$ and lymph nodes $(\mathrm{P}=0.006)$. In a confounder-adjusted multivariate regression model, miR-34a methylation provided the most significant prognostic information concerning metastasis to the liver $(\mathrm{P}=0.014)(61)$.

Inactivation of miR-200 members by DNA methylation has been described in various cancers (76-78). In a previous study, the authors demonstrated that the 5'-CGIs of both miR-200 loci are unmethylated and are associated with the expression of the corresponding miRNAs with epithelial features, whereas CGI hypermethylation-associated silencing is observed in transformed cells with mesenchymal characteristics (78). Additional studies revealed that miR-200ba429 and miR-200c141 transcripts undergo a dynamic epigenetic regulation linked to EMT or mesenchymal-to-epithelial transition (MET) phenotypes in tumour progression. These findings confirmed that the epigenetic silencing plasticity of the miR-200 family contributes to EMT and MET, and the development of CRC tumourigenesis (79).

Inflammatory bowel disease (IBD), including ulcerative colitis (UC) and Crohn's disease, is one of the most key high-risk conditions for CRC (80). Although it is known that epithelial dysplasia occurring in long-standing IBD is a typical precancerous lesion, the pathogenesis of colon cancer in IBD is poorly understood. Several studies have demonstrated the crucial role of altered miRNAs in the carcinogenesis of 
IBD-associated CRC (56,81-83), which includes the detection of epigenetic regulation of miRNAs. By comparing the expression and promoter methylation status of miR-124a in tissue samples from UC patients with or without CRC, patients with sporadic CRC and healthy volunteers, Ueda et al observed significantly decreased expression and higher methylation levels of miR-124a in UC-associated CRC (56). Downregulated miR-124 by hypermethylation was also identified in another study on UC, which promoted inflammation and the pathogenesis of UC by targeting STAT3 in paediatric patients (84).

Hypomethylation-reactivated miRNAs in CRC. Compared with silencing TSGs through DNA hypermethylation, hypomethylation activates oncogenes and promotes cancer progression. As a member of the let-7 miRNA family, let-7a has been reported as a tumour suppressor in CRC $(85,86)$. However, its expression was reactivated by DNA hypomethylation in lung cancer and was associated with enhanced tumour phenotypes and oncogenic changes (87). In a previous study of metastasis-related miRNAs in CRC, the authors observed a higher expression of miR-200c in liver metastases tissues than in primary CRCs (70). A functional analysis indicated that the overexpression of miR-200c induces MET in liver metastasis by targeting ZEB1, ETS1 and FLT1. More significantly, the increased expression of miR-200c was significantly associated with hypomethylation of the promoter region and was proven to be reactivated by the demethylation in CRC (70).

Histone modification-mediated regulation of miRNAs in CRC. Methylation is not the only epigenetic mechanism that affects miRNA expression. Histone modifications may also lead to either activation or repression of miRNAs depending on which residues are modified and which type of modification is present. The N-terminal tails of histones undergo several different covalent modifications, including acetylation, methylation, ubiquitylation, sumoylation and phosphorylation on specific residues (88).

Several studies have confirmed that HDAC inhibitor alters miRNA expression in CRC cells $(60,88-90)$. Acetylated lysine in histone tails was correlated with a more relaxed chromatin state and gene-transcription activation, whereas histone deacetylation led to a more compact chromatin structure and suppressed gene transcription (91). By combining the treatment of CRC cells with an HDAC inhibitor suberoylanilide hydroxamic acid (SAHA) and a microarray assay, Shin et al revealed that 32 of 275 human miRNAs were upregulated in HCT-116 cells, with the potential target genes related to apoptosis, cell cycle and differentiation of the cancer cells (90). Using another HDAC inhibitor, butyrate, which may decrease gene transcription by reducing histone $\mathrm{H} 3$ and $\mathrm{H} 4$ acetylation near the transcription start sites (92), Hu et al downregulated the expression of miR-106b in HCT-116 cells, restored p21 protein expression and decreased cell proliferation (89). Similarly, the expression of the oncogenic miR-17-92 cluster was inhibited by butyrate in HT29 and HCT116 CRC cells, with a corresponding increase in the target TSGs, including PTEN, BCL2L11 and CDKN1A (60).

In addition to performing their individual roles, DNA methylation and histone modifications interact with each other at manifold levels to influence chromatin organisation and the expression status of genes, including miRNAs. By comparing miRNA expression and histone modifications (H3K4me3, H3K27me3 and H3K79me2) before and after DNA demethylation, 47 miRNAs, including miR-1-1, were identified to be potential targets of epigenetic silencing and may act as a tumour suppressors in early and advanced CRC. DNA demethylation induced the upregulation of $\mathrm{H} 3 \mathrm{~K} 4 \mathrm{me} 3$ and $\mathrm{H} 3 \mathrm{~K} 27 \mathrm{me} 3$, but not H3K79me2, at the promoters of these miRNAs. The conclusion provided additional insight into the association between hypermethylation, chromatin modifications and miRNA dysregulation in cancer (54).

\section{5. miRNA regulatory effects on epigenetic machinery in CRC}

The significance of inhibitory signals that contribute to epigenetic gene silencing, including DNA methylation, histone modification and miRNAs, has been increasingly recognised in recent years. However, the crosstalk between these epigenetic regulators is not fully understood. An increasing amount of data exists to support miRNA regulation of the expression of components of the epigenetic machinery, creating a highly controlled feedback mechanism.

miRNAs regulate DNA methylation in CRC. Methylation changes to the genome are controlled by DNMTs. To date, three catalytically active DNMTs, namely DNMT1, DNMT3A and DNMT3B, have been identified (93). miR-143 has been confirmed to be a tumour suppressor miRNA and to decrease in CRC cells and tissues according to several studies (47,94-97). Moreover, DNMT3A, which represents an essential controller of methylation changes to the genome and is frequently increased in various malignancies including CRC, was defined as a direct target of miR-143 (98). Specifically, miR-143 was inversely correlated with mRNA and protein expression of DNMT3A in CRC. In silico prediction illustrated the binding of miR-143 with the DNMT3A 3' UTR, which was confirmed by a luciferase reporter assay. Furthermore, the restoration of miR-143 expression in colon cell lines downregulated DNMT3A expression at the mRNA and protein level.

Similarly, Wang et al demonstrated that DNMT1 is regulated by miR-342 in CRC (99). Low expression of miR-342 and high expression of DNMT1 were observed in CRC tissues and cell lines. Restoring miR-342 resulted in reduced DNMT1 expression and reduced cell proliferation as well as invasiveness in CRC cells and inhibition of tumour growth and lung metastasis formation in nude mice. More significantly, the ectopic expression of miR-342 decreased DNMT1 expression and reactivated TSGs, including ADAM23, Hint1, RASSF1A and RECKS, through promoter hypomethylation.

miRNAs regulate histone deacetylation in $C R C$. In addition to DNA methyltransferases, miRNA has been proven to regulate histone deacetylases in CRC. As a nicotinamide adenine dinucleotide-dependent deacetylase, silent information regulator 1 (SIRT1) may function as an oncogene and play a role in cancers including CRC (100-102). Yamakuchi et al demonstrated that miR-34a inhibits SIRT1 expression through a special binding site within the 3' UTR of SIRT1. miR-34a inhibition of SIRT1 leads to an increase in acetylated p53 
Table II. Regulation of epigenetic factors by miRNAs in CRC.

\begin{tabular}{lcccc}
\hline miRNA & Chromosomal location & Target gene & Expression in CRC & References \\
\hline miR-342 & $14 \mathrm{q} 32.2$ & DNMT1 & Downregulation \\
miR-140 & & HDAC4 & Downregulation \\
miR-627 & $16 \mathrm{q} 22.1$ & JMJD1A & Downregulation \\
miR-34a & $1 \mathrm{p} 36.22$ & MTA2, HDAC1 & Downregulation \\
miR-34a & $1 \mathrm{p} 36.22$ & SIRT1 & Downregulation \\
miR-137 & $1 \mathrm{p} 21.3$ & LSD1 & Downregulation \\
miR-143 & $5 \mathrm{q} 32$ & DNMT3A & Downregulation
\end{tabular}

CRC, colorectal cancer; $\mathrm{miR} / \mathrm{miRNA}$, microRNA.

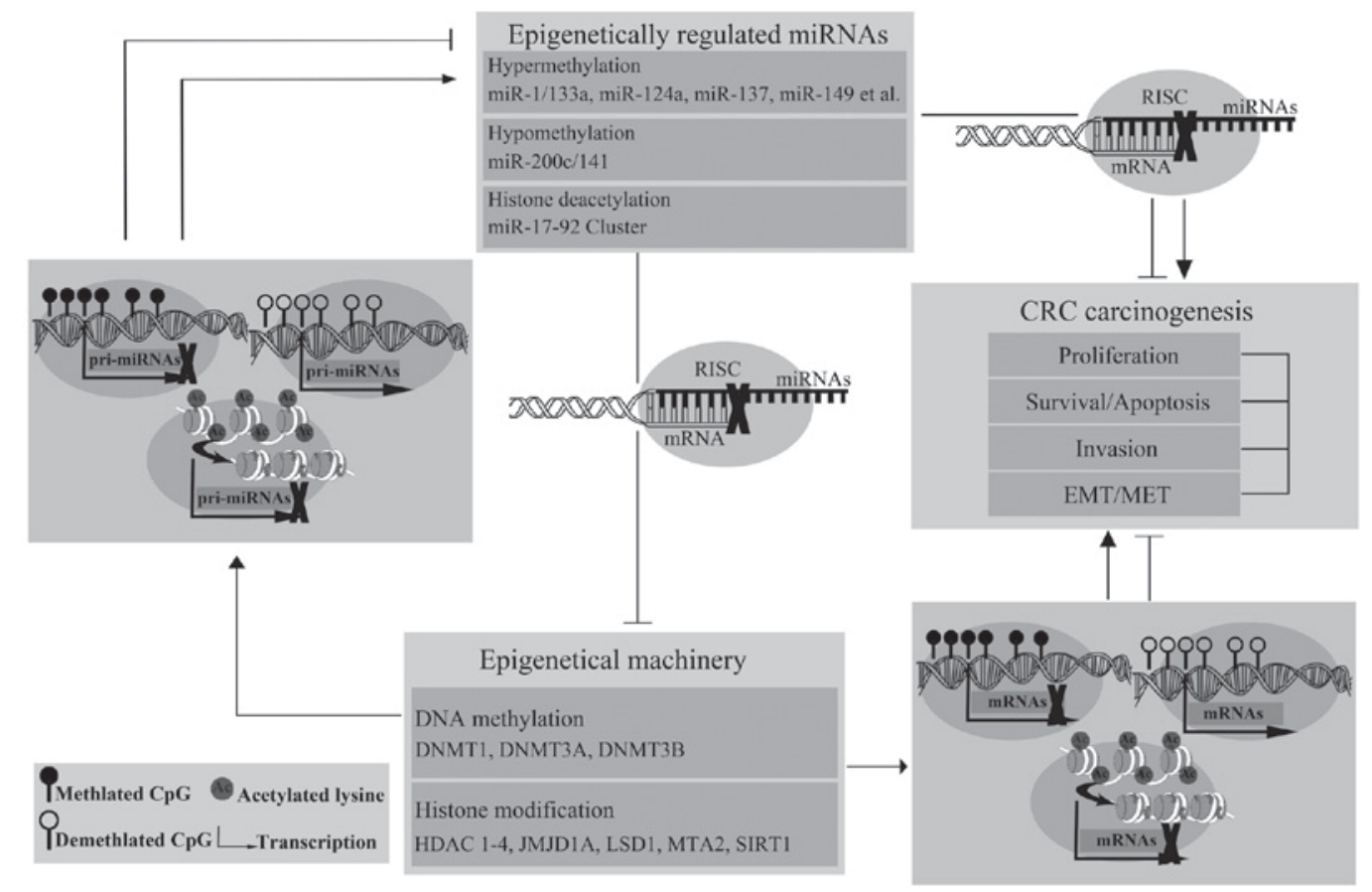

Figure 1. Schematic diagram of reciprocal crosstalk between microRNAs (miRNAs) and epigenetic regulators in colorectal cancer (CRC). Special pathological conditions result in the formation of an intricate regulatory circuit between miRNAs and various epigenetic mechanisms, involving DNA methylation and histone modifications. The epigenetic-miRNA interplay accounts for the development of CRC by post-transcriptional regulating oncogenes and tumour suppressor genes involved in CRC carcinogenesis. Regular arrow, positive interaction; T-shaped arrow, negative interaction.

and apoptosis in CRC cells. Furthermore, miR-34a is a transcriptional target of $\mathrm{p} 53$, suggesting a positive feedback loop between p53 and miR-34a through SIRT1-dependent regulation (103). Notably, another study reported that HDAC1 also exhibits a robust decrease in protein levels following the induction of miR-34a in CRC cells (104). In a previous study evaluating the role of miRNAs in the antitumour action of calcitriol, miRNA expression profiles were examined in colon cancer cells treated with calcitriol (105). The results revealed that calcitriol selectively induces the expression of miR-627. Moreover, histone demethylase JMJD1A was identified as the direct target of miR-627, suggesting that miR-627-mediated JMJD1A downregulation is an essential intracellular target for calcitriol and mediates epigenetic activities of calcitriol. The series of studies showing miRNAs regulating DNMTs or HDACs in CRC are listed in Table II.

\section{6. miRNAs mediate crosstalk between epigenetic regula- tors in CRC}

The same miRNA that provides epigenetic regulation may in turn affect the epigenetic machinery. miR-143, targeting DNMT3A in CRC cells, was hypermethylated and decreased in acute lymphoblastic leukaemia (ALL) cells. Demethylation restored functional endogenous miR-143 expression and significantly inhibited proliferation and induced apoptosis in ALL (106). On the one hand, CGI methylation of miR-148a and miR-152 genes regulated by DNMT1 silenced the TSG-like miRNAs in CRC (107-109). On the other hand, the levels of DNMT1, a direct target of miR-148a and miR-152, were inhibited by miR-148a and miR-152 overexpression. A negative feedback loop between DNMT1 and miR-148a/152 promoted carcinogenesis in cancer cells $(110,111)$, implying 
that miRNAs mediate the crosstalk between epigenetic regulators.

miR-137 has been identified as another significant mediator of crosstalk between epigenetic regulators in CRC. Balaguer et al revealed that miR-137 is constitutively expressed in the normal colonic epithelium and is silenced by CGI methylation of the promoter in neoplastic tissues (58). Restoring miR-137 expression in CRC cells resulted in a significant decrease in proliferation, suggesting its potential as a tumour suppressor miRNA in CRC. An additional analysis of candidate targets was performed using a combination of bioinformatic and transcriptomic approaches and identified that LSD1, an HDAC, is a target of miR-137. Notably, as a new class of histone demethylating enzymes, LSD1 was essential for the maintenance of global DNA methylation through the demethylation of a non-histone substrate, DNMT1, by increasing its stability. The results implied that miR-137 mediates the interplay between epigenetic regulators in CRC (58). All of these observations suggested a reciprocal crosstalk between miRNAs and epigenetic regulators. In this scenario, miRNAs functioned as a crucial factor in the valid transmission of various patterns of epigenetic modulation and thereby interfered with CRC carcinogenesis (Fig. 1).

\section{Clinical significance and future prospects}

The evidence discussed here indicates a strong interplay between miRNAs and epigenetic regulators in CRC. Epigenetically regulated miRNAs by DNA methylation or histone modifications are capable of silencing specific target molecules at the post-transcriptional level, including members of the epigenetic machinery, thus contributing to the conversation between other epigenetic events. These results have extended our comprehension of the pathogenesis and pathophysiology of CRC.

Additional exploration is warranted to annotate the regulatory loop involving miRNAs and the epigenetic machinery, and to explore how to translate these findings into clinical applications. First, it is crucial to identify new avenues for anticancer therapy based on the epigenetic regulation of miRNAs. To date, therapy using several epigenetic-based synthetic agents has been based on conventional protein-coding TSGs. With the identification of a greater number of epigenetically silenced tumour-suppressor miRNA genes in CRC, restoring these miRNAs using epigenetic agents is likely to become a potentially powerful approach to the remedy. Second, endeavours utilising miRNAs to modulate the expression levels of oncogenes and suppressor genes or to control the effector enzymes using epigenetic machinery and thus affecting the expression of a broad range of modulated molecules would permit the development of novel preventative therapies or adjunctive therapeutic approaches in CRC.

\section{Acknowledgements}

This study was supported by grants from the Shanghai Natural Science Foundation (grant no. 12ZR1447500), the National Natural Science Foundation of China (grant no. 81301753), the Specialized Research Fund for the Doctoral Program of Higher Education (grant no. 20130072120046), and the State
Key Program of the National Natural Science Foundation of China (grant no. 81230057).

\section{References}

1. Center MM, Jemal A, Smith RA and Ward E: Worldwide variations in colorectal cancer. CA Cancer J Clin 59: 366-378, 2009.

2. Jones PA and Baylin SB: The epigenomics of cancer. Cell 128: 683-692, 2007.

3. Zhang B, Pan X, Cobb GP and Anderson TA: microRNAs as oncogenes and tumor suppressors. Dev Biol 302: 1-12, 2007.

4. Bartel DP: MicroRNAs: Genomics, biogenesis, mechanism and function. Cell 116: 281-297, 2004.

5. Kong YW, Ferland-McCollough D, Jackson TJ and Bushell M: microRNAs in cancer management. Lancet Oncol 13: e249-e258, 2012.

6. Lujambio A and Lowe SW: The microcosmos of cancer. Nature 482: 347-355, 2012.

7. Lee RC, Feinbaum RL and Ambros V: The C. elegans heterochronic gene lin-4 encodes small RNAs with antisense complementarity to lin-14. Cell 75: 843-854, 1993.

8. Kozomara A and Griffiths-Jones S: miRBase: annotating high confidence microRNAs using deep sequencing data. Nucleic Acids Res 42 (Database Issue): D68-D73, 2014.

9. Lu J, Getz G, Miska EA, Alvarez-Saavedra E, Lamb J, Peck D, Sweet-Cordero A, Ebert BL, Mak RH, Ferrando AA, et al: MicroRNA expression profiles classify human cancers. Nature 435: 834-838, 2005

10. Grady WM and Tewari M: The next thing in prognostic molecular markers: microRNA signatures of cancer. Gut 59: 706-708, 2010.

11. Goel A and Boland CR: Epigenetics of colorectal cancer. Gastroenterology 143: 1442.e1-1460.e1, 2012.

12. Schwarzenbach H, Nishida N, Calin GA and Pantel K: Clinical relevance of circulating cell-free microRNAs in cancer. Nat Rev Clin Oncol 11: 145-156, 2014.

13. Michael MZ, O'Connor SM, van Holst Pellekaan NG, Young GP and James RJ: Reduced accumulation of specific microRNAs in colorectal neoplasia. Mol Cancer Res 1: 882-891, 2003.

14. Schetter AJ, Leung SY, Sohn JJ, Zanetti KA, Bowman ED, Yanaihara N, Yuen ST, Chan TL, Kwong DL, Au GK, et al: MicroRNA expression profiles associated with prognosis and therapeutic outcome in colon adenocarcinoma. JAMA 299: 425-436, 2008.

15. Rohr C, Kerick M, Fischer A, Kühn A, Kashofer K, Timmermann B, Daskalaki A, Meinel T, Drichel D, Börno ST, et al: High-throughput miRNA and mRNA sequencing of paired colorectal normal, tumor and metastasis tissues and bioinformatic modeling of miRNA-1 therapeutic applications. PLoS One 8: e67461, 2013.

16. Pencheva $\mathrm{N}$ and Tavazoie SF: Control of metastatic progression by microRNA regulatory networks. Nat Cell Biol 15: 546-554, 2013.

17. Qian B, Nag SA, Su Y, Voruganti S, Qin JJ, Zhang R and Cho WC: MiRNAs in cancer prevention and treatment and as molecular targets for natural product anticancer agents. Curr Cancer Drug Targets 13: 519-541, 2013.

18. Suzuki HI, Katsura A, Matsuyama $\mathrm{H}$ and Miyazono $\mathrm{K}$ : MicroRNA regulons in tumor microenvironment. Oncogene 34: 3085-3094, 2015.

19. Berindan-Neagoe I, Monroig Pdel C, Pasculli B and Calin GA: MicroRNAome genome: a treasure for cancer diagnosis and therapy. CA Cancer J Clin 64: 311-336, 2014.

20. Lewis BP, Burge CB and Bartel DP: Conserved seed pairing, often flanked by adenosines, indicates that thousands of human genes are microRNA targets. Cell 120: 15-20, 2005.

21. Hermeking H: MicroRNAs in the p53 network: micromanagement of tumour suppression. Nat Rev Cancer 12: 613-626, 2012.

22. Giordano S and Columbano A: MicroRNAs: new tools for diagnosis, prognosis and therapy in hepatocellular carcinoma? Hepatology 57: 840-847, 2013.

23. Weisenberger DJ: Characterizing DNA methylation alterations from the cancer Genome Atlas. J Clin Invest 124: 17-23, 2014.

24. Xue B and He L: An expanding universe of the non-coding genome in cancer biology. Carcinogenesis 35: 1209-1216, 2014. 
25. Ballestrero A, Garuti A, Cirmena G, Rocco I, Palermo C, Nencioni A, Scabini S, Zoppoli G, Parodi S and Patrone F: Patient-tailored treatments with anti-EGFR monoclonal antibodies in advanced colorectal cancer: KRAS and beyond. Curr Cancer Drug Targets 12: 316-328, 2012.

26. Kent OA, McCall MN, Cornish TC and Halushka MK: Lessons from miR-143/145: the importance of cell-type localization of miRNAs. Nucleic Acids Res 42: 7528-7538, 2014.

27. Segditsas $\mathrm{S}$ and Tomlinson I: Colorectal cancer and genetic alterations in the Wnt pathway. Oncogene 25: 7531-7537, 2006

28. Ma Y, Zhang P, Wang F, Zhang H, Yang Y, Shi C, Xia Y, Peng J, Liu W, Yang Z and Qin H: Elevated oncofoetal miR-17-5p expression regulates colorectal cancer progression by repressing its target gene P130. Nat Commun 3: 1291, 2012.

29. Strillacci A, Valerii MC, Sansone P, Caggiano C, Sgromo A Vittori L, Fiorentino M, Poggioli G, Rizzello F, Campieri M and Spisni E: Loss of miR-101 expression promotes Wnt/ $\beta$-catenin signalling pathway activation and malignancy in colon cancer cells. J Pathol 229: 379-389, 2013

30. Vermeulen L, De Sousa E Melo F, van der Heijden M, Cameron K, de Jong JH, Borovski T, Tuynman JB, Todaro M, Merz C, Rodermond $\mathrm{H}$, et al: Wnt activity defines colon cancer stem cells and is regulated by the microenvironment. Nat Cell Biol 12: 468-476, 2010

31. Le Grand F, Jones AE, Seale V, Scimè A and Rudnicki MA: Wnt7a activates the planar cell polarity pathway to drive the symmetric expansion of satellite stem cells. Cell Stem Cell 4: 535-547, 2009

32. Hwang WL, Jiang JK, Yang SH, Huang TS, Lan HY Teng HW, Yang CY, Tsai YP, Lin CH, Wang HW and Yang MH: MicroRNA-146a directs the symmetric division of Snail-dominant colorectal cancer stem cells. Nat Cell Biol 16 : 268-280, 2014

33. Carstens JL, Lovisa $\mathrm{S}$ and Kalluri R: Microenvironment-dependent cues trigger miRNA-regulated feedback loop to facilitate the EMT/MET switch. J Clin Invest 124: 1458-1460, 2014.

34. Zhang JX, Mai SJ, Huang XX, Wang FW, Liao YJ, Lin MC, Kung HF, Zeng YX and Xie D: MiR-29c mediates epithelial-to-mesenchymal transition in human colorectal carcinoma metastasis via PTP4A and GNA13 regulation of $\beta$-catenin signaling. Ann Oncol 25: 2196-2204, 2014.

35. Rokavec M, Öner MG, Li H, Jackstadt R, Jiang L, Lodygin D, Kaller M, Horst D, Ziegler PK, Schwitalla S, et al: IL-6R/STAT3/miR-34a feedback loop promotes EMT-mediated colorectal cancer invasion and metastasis. J Clin Invest 124: 1853-1867, 2014.

36. Chen X, Guo X, Zhang H, Xiang Y, Chen J, Yin Y, Cai X Wang K, Wang G, Ba Y, et al: Role of miR-143 targeting KRAS in colorectal tumorigenesis. Oncogene 28: 1385-1392, 2009.

37. Pagliuca A, Valvo C, Fabrizi E, di Martino S, Biffoni M, Runci D, Forte S, De Maria R and Ricci-Vitiani L: Analysis of the combined action of miR-143 and miR-145 on oncogenic pathways in colorectal cancer cells reveals a coordinate program of gene repression. Oncogene 32: 4806-4813, 2013.

38. Tsang WP and Kwok TT: The miR-18a* microRNA functions as a potential tumor suppressor by targeting on K-Ras. Carcinogenesis 30: 953-959, 2009

39. Liao WT, Ye YP, Zhang NJ, Li TT, Wang SY, Cui YM, Qi L, Wu P, Jiao HL, Xie YJ, et al: MicroRNA-30b functions as a tumour suppressor in human colorectal cancer by targeting KRAS, PIK3CD and BCL2. J Pathol 232: 415-427, 2014.

40. Sebio A, Paré L, Pàez D, Salazar J, González A, Sala N, del Río E, Martín-Richard M, Tobeña M, Barnadas A and Baiget M: The LCS6 polymorphism in the binding site of let-7 microRNA to the KRAS 3'-untranslated region: its role in the efficacy of anti-EGFR-based therapy in metastatic colorectal cancer patients. Pharmacogenet Genomics 23: 142-147, 2013.

41. Ota T, Doi K, Fujimoto T, Tanaka Y, Ogawa M, Matsuzaki H, Kuroki M, Miyamoto S, Shirasawa S and Tsunoda T: KRAS up-regulates the expression of miR-181a, miR-200c and miR-210 in a three-dimensional-specific manner in DLD-1 colorectal cancer cells. Anticancer Res 32: 2271-2275, 2012.

42. Ciardiello F and Tortora G: EGFR antagonists in cancer treatment. N Engl J Med 358: 1160-1174, 2008.

43. Lièvre A, Bachet JB, Boige V, Cayre A, Le Corre D, Buc E, Ychou M, Bouché O, Landi B, Louvet C, et al: KRAS mutations as an independent prognostic factor in patients with advanced colorectal cancer treated with cetuximab. J Clin Oncol 26: 374-379, 2008
44. Manceau G, Imbeaud S, Thiébaut R, Liébaert F, Fontaine K, Rousseau F, Génin B, Le Corre D, Didelot A, Vincent M, et al: Hsa-miR-31-3p expression is linked to progression-free survival in patients with KRAS wild-type metastatic colorectal cancer treated with anti-EGFR therapy. Clin Cancer Res 20: 3338-3347, 2014.

45. Saridaki Z, Weidhaas JB, Lenz HJ, Laurent-Puig P, Jacobs B, De Schutter J, De Roock W, Salzman DW, Zhang W, Yang D, et al: A let-7 microRNA-binding site polymorphism in KRAS predicts improved outcome in patients with metastatic colorectal cancer treated with salvage cetuximab/panitumumab monotherapy. Clin Cancer Res 20: 4499-4510, 2014.

46. Pichler M, Winter E, Ress AL, Bauernhofer T, Gerger A, Kiesslich T, Lax S, Samonigg H and Hoefler G: MiR-181a is associated with poor clinical outcome in patients with colorectal cancer treated with EGFR inhibitor. J Clin Pathol 67: 198-203, 2014

47. Pichler M, Winter E, Stotz M, Eberhard K, Samonigg H, Lax S and Hoefler G: Down-regulation of KRAS-interacting miRNA-143 predicts poor prognosis but not response to EGFR-targeted agents in colorectal cancer. Br J Cancer 106: 1826-1832, 2012

48. Fabbri $\mathrm{M}$ and Calin GA: Epigenetics and miRNAs in human cancer. Adv Genet 70: 87-99, 2010.

49. Toyota M, Suzuki H, Sasaki Y, Maruyama R, Imai K Shinomura $\mathrm{Y}$ and Tokino $\mathrm{T}$ : Epigenetic silencing of microRNA-34b/c and B-cell translocation gene 4 is associated with $\mathrm{CpG}$ island methylation in colorectal cancer. Cancer Res 68: 4123-4132, 2008

50. Vinci S, Gelmini S, Mancini I, Malentacchi F, Pazzagli M, Beltrami C, Pinzani P and Orlando C: Genetic and epigenetic factors in regulation of microRNA in colorectal cancers. Methods 59: 138-146, 2013

51. Lujambio A, Ropero S, Ballestar E, Fraga MF, Cerrato C, Setién F, Casado S, Suarez-Gauthier A, Sanchez-Cespedes M, Git A, et al: Genetic unmasking of an epigenetically silenced microRNA in human cancer cells. Cancer Res 67: 1424-1429, 2007.

52. Bandres E, Agirre X, Bitarte N, Ramirez N, Zarate R, Roman-Gomez J, Prosper F and Garcia-Foncillas J: Epigenetic regulation of microRNA expression in colorectal cancer. Int J Cancer 125: 2737-2743, 2009.

53. Chen WS, Leung CM, Pan HW, Hu LY, Li SC, Ho MR and Tsai KW: Silencing of miR-1-1 and miR-133a-2 cluster expression by DNA hypermethylation in colorectal cancer. Oncol Rep 28: 1069-1076, 2012.

54. Suzuki H, Takatsuka S, Akashi H, Yamamoto E, Nojima M, Maruyama R, Kai M, Yamano HO, Sasaki Y, Tokino T, et al: Genome-wide profiling of chromatin signatures reveals epigenetic regulation of MicroRNA genes in colorectal cancer. Cancer Res 71: 5646-5658, 2011.

55. Deng G, Kakar S and Kim YS: MicroRNA-124a and microRNA-34b/c are frequently methylated in all histological types of colorectal cancer and polyps and in the adjacent normal mucosa. Oncol Lett 2: 175-180,2011.

56. Ueda Y, Ando T, Nanjo S, Ushijima T and Sugiyama T: DNA methylation of microRNA-124a is a potential risk marker of colitis-associated cancer in patients with ulcerative colitis. Dig Dis Sci 59: 2444-2451, 2014

57. Grady WM, Parkin RK, Mitchell PS, Lee JH, Kim YH, Tsuchiya KD, Washington MK, Paraskeva C, Willson JK, Kaz AM, et al: Epigenetic silencing of the intronic microRNA hsa-miR-342 and its host gene EVL in colorectal cancer. Oncogene 27: 3880-3888, 2008.

58. Balaguer F, Link A, Lozano JJ, Cuatrecasas M, Nagasaka T, Boland CR and Goel A: Epigenetic silencing of miR-137 is an early event in colorectal carcinogenesis. Cancer Res 70: 6609-6618, 2010.

59. Yan $\mathrm{H}$, Choi AJ, Lee $\mathrm{BH}$ and Ting $\mathrm{AH}$ : Identification and functional analysis of epigenetically silenced microRNAs in colorectal cancer cells. PLoS One 6: e20628, 2011.

60. Humphreys KJ, Cobiac L, Le Leu RK, Van der Hoek MB and Michael MZ: Histone deacetylase inhibition in colorectal cancer cells reveals competing roles for members of the oncogenic miR-17-92 cluster. Mol Carcinog 52: 459-474, 2013

61. Siemens H, Neumann J, Jackstadt R, Mansmann U, Horst D, Kirchner T and Hermeking H: Detection of miR-34a promoter methylation in combination with elevated expression of c-Met and $\beta$-catenin predicts distant metastasis of colon cancer. Clin Cancer Res 19: 710-720, 2013. 
62. Takahashi Y, Iwaya T, Sawada G, Kurashige J, Matsumura T, Uchi R, Ueo H, Takano Y, Eguchi H, Sudo T, et al: Up-regulation of NEK2 by microRNA-128 methylation is associated with poor prognosis in colorectal cancer. Ann Surg Oncol 21: 205-212, 2014

63. Sun J, Song Y, Wang Z, Wang G, Gao P, Chen X, Gao Z and $\mathrm{Xu} \mathrm{H}$ : Clinical significance of promoter region hypermethylation of microRNA-148a in gastrointestinal cancers. Onco Targets Ther 7: 853-863, 2014.

64. Cho WC: Epigenetic alteration of microRNAs in feces of colorectal cancer and its clinical significance. Expert Rev Mol Diagn 11: 691-694, 2011

65. Zhang Y, Wang X, Xu B, Wang B, Wang Z, Liang Y, Zhou J, $\mathrm{Hu} \mathrm{J}$ and Jiang B: Epigenetic silencing of miR-126 contributes to tumor invasion and angiogenesis in colorectal cancer. Oncol Rep 30: 1976-1984, 2013.

66. Ye J, Wu X, Wu D, Wu P, Ni C, Zhang Z, Chen Z, Qiu F, Xu J and Huang J: miRNA-27b targets vascular endothelial growth factor $\mathrm{C}$ to inhibit tumor progression and angiogenesis in colorectal cancer. PLoS One 8: e60687, 2013.

67. Wang F, Ma YL, Zhang P, Shen TY, Shi CZ, Yang YZ, Moyer MP, Zhang HZ, Chen HQ, Liang Y and Qin HL: SP1 mediates the link between methylation of the tumour suppressor miR-149 and outcome in colorectal cancer. J Pathol 229: 12-24, 2013.

68. Menigatti M, Staiano T, Manser CN, Bauerfeind $\mathrm{P}$, Komljenovic A, Robinson M, Jiricny J, Buffoli F and Marra G: Epigenetic silencing of monoallelically methylated miRNA loci in precancerous colorectal lesions. Oncogenesis 2: e56, 2013.

69. Meng X, Wu J, Pan C, Wang H, Ying X, Zhou Y, Yu H, Zuo Y, Pan Z, Liu RY and Huang W: Genetic and epigenetic down-regulation of microRNA-212 promotes colorectal tumor metastasis via dysregulation of MnSOD. Gastroenterology 145: 426-436.e1-e6, 2013.

70. Hur K, Toiyama Y, Takahashi M, Balaguer F, Nagasaka T, Koike J, Hemmi H, Koi M, Boland CR and Goel A: MicroRNA-200c modulates epithelial-to-mesenchymal transition (EMT) in human colorectal cancer metastasis. Gut 62: 1315-1326, 2013

71. Tang JT, Wang JL, Du W, Hong J, Zhao SL, Wang YC, Xiong H, Chen HM and Fang JY: MicroRNA 345, a methylation-sensitive microRNA is involved in cell proliferation and invasion in human colorectal cancer. Carcinogenesis 32: 1207-1215, 2011.

72. Tanaka T, Arai M, Wu S, Kanda T, Miyauchi H, Imazeki F, Matsubara $\mathrm{H}$ and Yokosuka O: Epigenetic silencing of microRNA-373 plays an important role in regulating cell proliferation in colon cancer. Oncol Rep 26: 1329-1335, 2011.

73. Hinoue T, Weisenberger DJ, Lange CP, Shen H, Byun HM, Van Den Berg D, Malik S, Pan F, Noushmehr H, van Dijk CM, et al: Genome-scale analysis of aberrant DNA methylation in colorectal cancer. Genome Res 22: 271-282, 2012

74. Weber B, Stresemann C, Brueckner B and Lyko F: Methylation of human microRNA genes in normal and neoplastic cells. Cell Cycle 6: 1001-1005, 2007

75. Christman JK: 5-Azacytidine and 5-aza-2'-deoxycytidine as inhibitors of DNA methylation: mechanistic studies and their implications for cancer therapy. Oncogene 21: 5483-5495, 2002

76. Ceppi P, Mudduluru G, Kumarswamy R, Rapa I, Scagliotti GV Papotti $\mathrm{M}$ and Allgayer H: Loss of miR-200c expression induces an aggressive, invasive and chemoresistant phenotype in non-small cell lung cancer. Mol Cancer Res 8: 1207-1216, 2010.

77. Vrba L, Jensen TJ, Garbe JC, Heimark RL, Cress AE, Dickinson S, Stampfer MR and Futscher BW: Role for DNA methylation in the regulation of miR-200c and miR-141 expression in normal and cancer cells. PLoS One 5: e8697, 2010.

78. Wiklund ED, Bramsen JB, Hulf T, Dyrskjøt L, Ramanathan R, Hansen TB, Villadsen SB, Gao S, Ostenfeld MS, Borre M, et al: Coordinated epigenetic repression of the miR-200 family and miR-205 in invasive bladder cancer. Int J Cancer 128 : 1327-1334, 2011

79. Davalos V, Moutinho C, Villanueva A, Boque R, Silva P, Carneiro $\mathrm{F}$ and Esteller M: Dynamic epigenetic regulation of the microRNA-200 family mediates epithelial and mesenchymal transitions in human tumorigenesis. Oncogene 31 : 2062-2074, 2012.

80. Hartnett L and Egan LJ: Inflammation, DNA methylation and colitis-associated cancer. Carcinogenesis 33: 723-731, 2012.
81. Valeri N, Braconi C, Gasparini P, Murgia C, Lampis A, Paulus-Hock V, Hart JR, Ueno L, Grivennikov SI, Lovat F, et al: MicroRNA-135b promotes cancer progression by acting as a downstream effector of oncogenic pathways in colon cancer. Cancer Cell 25: 469-483, 2014.

82. Wu CW, Ng SC, Dong Y, Tian L, Ng SS, Leung WW, Law WT, Yau TO, Chan FK, Sung JJ and Yu J: Identification of microRNA-135b in stool as a potential noninvasive biomarker for colorectal cancer and adenoma. Clin Cancer Res 20 : 2994-3002, 2014.

83. Kanaan Z, Rai SN, Eichenberger MR, Barnes C, Dworkin AM, Weller C, Cohen E, Roberts H, Keskey B, Petras RE, et al: Differential microRNA expression tracks neoplastic progression in inflammatory bowel disease-associated colorectal cancer. Hum Mutat 33: 551-560, 2012.

84. Koukos G, Polytarchou C, Kaplan JL, Morley-Fletcher A, Gras-Miralles B, Kokkotou E, Baril-Dore M, Pothoulakis C, Winter HS and Iliopoulos D: MicroRNA-124 regulates STAT3 expression and is down-regulated in colon tissues of pediatric patients with ulcerative colitis. Gastroenterology 145 : 842-852 e2, 2013.

85. Johnson CD, Esquela-Kerscher A, Stefani G, Byrom M, Kelnar K, Ovcharenko D, Wilson M, Wang X, Shelton J, Shingara J, et al: The let-7 microRNA represses cell proliferation pathways in human cells. Cancer Res 67: 7713-7722, 2007.

86. Wang F, Zhang P, Ma Y, Yang J, Moyer MP, Shi C, Peng J and Qin H: NIRF is frequently upregulated in colorectal cancer and its oncogenicity can be suppressed by let-7a microRNA. Cancer Lett 314: 223-231, 2012.

87. Brueckner B, Stresemann C, Kuner R, Mund C, Musch T, Meister M, Sültmann H and Lyko F: The human let-7a-3 locus contains an epigenetically regulated microRNA gene with oncogenic function. Cancer Res 67: 1419-1423, 2007.

88. Kouzarides T: Chromatin modifications and their function. Cell 128: 693-705, 2007.

89. Hu S, Dong TS, Dalal SR, Wu F, Bissonnette M, Kwon JH and Chang EB: The microbe-derived short chain fatty acid butyrate targets miRNA-dependent $\mathrm{p} 21$ gene expression in human colon cancer. PLoS One 6: e16221, 2011.

90. Shin S, Lee EM, Cha HJ, Bae S, Jung JH, Lee SM, Yoon Y, Lee H, Kim S, Kim H, et al: MicroRNAs that respond to histone deacetylase inhibitor SAHA and p53 in HCT116 human colon carcinoma cells. Int J Oncol 35: 1343-1352, 2009.

91. Falkenberg KJ and Johnstone RW: Histone deacetylases and their inhibitors in cancer, neurological diseases and immune disorders. Nat Rev Drug Discov 13: 673-691, 2014.

92. Rada-Iglesias A, Enroth S, Ameur A, Koch CM, Clelland GK, Respuela-Alonso P, Wilcox S, Dovey OM, Ellis PD, Langford CF, et al: Butyrate mediates decrease of histone acetylation centered on transcription start sites and down-regulation of associated genes. Genome Res 17: 708-719, 2007.

93. Jeltsch A: Beyond Watson and Crick: DNA methylation and molecular enzymology of DNA methyltransferases. Chembiochem 3: 274-293, 2002.

94. Borralho PM, Kren BT, Castro RE, da Silva IB, Steer CJ and Rodrigues CM: MicroRNA-143 reduces viability and increases sensitivity to 5-fluorouracil in HCT116 human colorectal cancer cells. FEBS J 276: 6689-6700, 2009.

95. Zhang Y, Wang Z, Chen M, Peng L, Wang X, Ma Q, Ma F and Jiang B: MicroRNA-143 targets MACC1 to inhibit cell invasion and migration in colorectal cancer. Mol Cancer 11: 23, 2012.

96. Gregersen LH, Jacobsen A, Frankel LB, Wen J, Krogh A and Lund AH: MicroRNA-143 down-regulates Hexokinase 2 in colon cancer cells. BMC Cancer 12: 232, 2012.

97. Qian X, Yu J, Yin Y, He J, Wang L, Li Q, Zhang LQ, Li CY, Shi ZM, Xu Q, et al: MicroRNA-143 inhibits tumor growth and angiogenesis and sensitizes chemosensitivity to oxaliplatin in colorectal cancers. Cell Cycle 12: 1385-1394, 2013.

98. Ng EK, Tsang WP, Ng SS, Jin HC, Yu J, Li JJ, Röcken C, Ebert MP, Kwok TT and Sung JJ: MicroRNA-143 targets DNA methyltransferases 3A in colorectal cancer. Br J Cancer 101: 699-706, 2009.

99. Wang H, Wu J, Meng X, Ying X, Zuo Y, Liu R, Pan Z, Kang T and Huang W: MicroRNA-342 inhibits colorectal cancer cell proliferation and invasion by directly targeting DNA methyltransferase 1. Carcinogenesis 32: 1033-1042, 2011.

100. Yeung F, Hoberg JE, Ramsey CS, Keller MD, Jones DR, Frye RA and Mayo MW: Modulation of NF-kappaB-dependent transcription and cell survival by the SIRT1 deacetylase. EMBO J 23: 2369-2380, 2004 
101. Huffman DM, Grizzle WE, Bamman MM, Kim JS, Eltoum IA Elgavish A and Nagy TR: SIRT1 is significantly elevated in mouse and human prostate cancer. Cancer Res 67: 6612-6618, 2007.

102. Kriegl L, Vieth M, Kirchner T and Menssen A: Up-regulation of c-MYC and SIRT1 expression correlates with malignant transformation in the serrated route to colorectal cancer. Oncotarget 3 : 1182-1193, 2012.

103. Yamakuchi M, Ferlito M and Lowenstein CJ: miR-34a repression of SIRT1 regulates apoptosis. Proc Natl Acad Sci USA 105: 13421-13426, 2008.

104. Kaller M, Liffers ST, Oeljeklaus S, Kuhlmann K, Röh S, Hoffmann R, Warscheid B and Hermeking H: Genome-wide characterization of miR-34a induced changes in protein and mRNA expression by a combined pulsed SILAC and microarray analysis. Mol Cell Proteomics 10: M111.010462, 2011.

105. Padi SK, Zhang Q, Rustum YM, Morrison C and Guo B: MicroRNA-627 mediates the epigenetic mechanisms of vitamin D to suppress proliferation of human colorectal cancer cells and growth of xenograft tumors in mice. Gastroenterology 145: 437-446, 2013.

106. Dou L, Zheng D, Li J, Li Y, Gao L, Wang L and Yu L: Methylation-mediated repression of microRNA-143 enhances MLL-AF4 oncogene expression. Oncogene 31: 507-517, 2012.
107. Chen Y, Song Y, Wang Z, Yue Z, Xu H, Xing C and Liu Z: Altered expression of MiR-148a and MiR-152 in gastrointestinal cancers and its clinical significance. J Gastrointest Surg 14: 1170-1179, 2010.

108. Pavicic W, Perkiö E, Kaur S and Peltomäki P: Altered methylation at microRNA-associated $\mathrm{CpG}$ islands in hereditary and sporadic carcinomas: a methylation-specific multiplex ligation-dependent probe amplification (MS-MLPA)-based approach. Mol Med 17: 726-735, 2011.

109. Takahashi M, Cuatrecasas M, Balaguer F, Hur K, Toiyama Y, Castells A, Boland CR and Goel A: The clinical significance of MiR-148a as a predictive biomarker in patients with advanced colorectal cancer. PLoS One 7: e46684, 2012.

110. Zhu A, Xia J, Zuo J, Jin S, Zhou H, Yao L, Huang H and Han Z: MicroRNA-148a is silenced by hypermethylation and interacts with DNA methyltransferase 1 in gastric cancer. Med Oncol 29: 2701-2709, 2012.

111. Xu Q, Jiang Y, Yin Y, Li Q, He J, Jing Y, Qi YT, Xu Q $\mathrm{Li} \mathrm{W}, \mathrm{Lu} \mathrm{B}$, et al: A regulatory circuit of miR-148a/152 and DNMT1 in modulating cell transformation and tumor angiogenesis through IGF-IR and IRS1. J Mol Cell Biol 5: 3-13, 2013. 